\title{
Digital multitasking problem in modern universities educational process - review
}

\author{
Tatyana Lyubova ${ }^{1}$ \\ ${ }^{1}$ Kazan Federal University, Department of Philology, Naberezhnye Chelny, Russia
}

\begin{abstract}
This article is a review of recent researches on digital multitasking problem. Claiming that digital technologies are changing the traditional roles of a teacher and a student, we must clearly understand a kind of effects arised at the moment digital technologies are used in the classroom. Moreover, the methods of applying digital technologies for the success of students' academic progress are not always obvious to the teacher himself. The goal of the research analysis on digital multitasking in education problem is to identify shifts in settings and accents from the operationalism methodology to attempts of application of analytical philosophy of consciousness methodology and / or postmodern philosophy. This allows us to analyze the intentions, motives of the educational process participants and thereby define new conceptual boundaries of digital multitasking.
\end{abstract}

\section{Introduction}

This article is useful for those who want to understand the contradictions in electronic education and the digital technologies used at universities, including scientists and practitioners, students, teachers and administrators. Do we need to rethink higher education again? Technological innovations mean constant updating of what we understand by the term "educational process". There is some continuity of thinking in education. It is necessary to clarify the nature of the relationship between pedagogy and information technology.

It is widely believed that education in the digital age should be implemented through the widespread use of information and communication technologies. Consequently, the traditional boundaries of education are expanding. Digital technologies in pedagogy are able to transform the relationship between the components of education. A serious problem in higher education is associated not only with the fact that students have unlimited access to growing Internet resources, but also with the students' real digital competence (Lyubova T.V., Gilfanova G.T. 2019). We must reconstruct education so that students can take control of their own learning. Universities create and provide opportunities that foster effective learning in the digital age. A significant amount of pedagogical research is devoted to the analysis of the actions of students with digital (information) technologies. Such studies provide a vivid idea of the complex lives of today's students and confirm the value of attracting students to important decisions. 
Of particular interest are recommendations that emphasize the need to prepare students for training in the digital age, including the development of their digital literacy. Undoubtedly, most students have extensive experience in applying digital technologies before entering university. The rest gain this experience after compulsory education. However, empirical studies show that familiarity with technology does not mean a student understands the patterns of its use. There is abundant evidence that, with widespread access to gadgets, students have difficulty using digital technology in an educational context. That is why an emphasis is placed on some technologies of training in the digital environment: discursive learning, a culture of participation, the use of social networks.

Around the middle of the last century, the digital revolution began as a multifactor transition from analog to digital processing, storage and transmission of data, and, accordingly, the rapid development of the hardware and software serving these processes. Changes begin with the research of innovations, which having a successful set of socioeconomic circumstances, reach industrial developments and mass usage. Some digital innovations overcome this path significantly faster, such as, for example, a tablet personal computer.

Other examples of important theoretical developmentsand their successful implementations are mathematical substantiation of the method of converting an analog signal to a digital one and vice versa by V. A. Kotelnikov (the reading theorem, 1933), the formalization of the principle of algorithmic processing for construction a digital computer by A. Turing (a Turing machine, 1936), principles and invention of an electromechanical programmable digital machine $\mathrm{K}$. Zuse $(Z 3,1941)$, an electronic digital computer J. Atanasova and K. Berry $(A B C, 1942)$, Harvard digital computing Mark-1 machines (G. Aiken, IBM, 1944), British Colossus (Mark 1, Mark 2, 1944), American (D. Mauchly, P. Eckert, ENIAC, 1946) and the Russian digital computer (SECM, 1950, BECM, 1952), etc. which became the forerunners of modern digital technology.

Most often, digital technologies and systems are mentioned in connection with multimedia formats of information representation and processing (for example, digital television, photo, video and audio equipment, as well as in connection with digital communication systems (for example, digital networks based on ISDN and xDSL. This is not surprising, since computers were called digital computers since the 1940s, the term (digital) electronic computer (computer) became common in the late 1960s, and the first personal computers appeared in the 1970s we continued to call as ECM by the existing Russian standards.

Around the sameyears methods of digitizing or digital image and sound processing began to be actively investigated and developed. Currently, the term computer has lost its original meaning and more popular term "computer" has appeared. Regardless of the name, all types of computers to varying degrees represent and process data (usually analog - texts, documents, numbers, tables, images, maps, drawings, image sequences / animation, threedimensional models, signals or sounds) in digital ( discrete) format. It is digital technology that allows you to manipulate data at high speed, including transmission via analog (continuous) or digital communication channels (analog-digital / digital-analog conversion, coding, modulation / demodulation of the signal). Computers, telecommunications, Internet network services have the ability to process these digital data, which are there thanks to the conversion (digitization, digitalization) of various types of analog signals. Then, in digital form, these data are combined by devices and programs into new formats, undergoing convergence or mediaconvergence.

According to our research, the density of the emergence of new digital systems and devices has increased significantly, approximately since the early 1970s. Their growing popularity is gradually leading to the displacement of traditional analog devices and systems. A vivid example is the intensive development of mobile (mobile) cellular 
communication, which surpasses fixed-line analog / digital telephony by the number of subscribers. According to a study published in Science Express, digital technologies began to dominate in the 1990 s and in $200799.9 \%$ of the information was transmitted in digital format. Scientists believe the beginning of the digital revolution is 2002, when the volume of digital data stored in the world for the first time exceeded the total volume of analog data. Most of these innovations Clayton Christensen and his followers refer to "disruptive" technologies, which unlike "supported" ones are capable to generate socio-economic changes in all spheres of human activity.

As for education, many of the revolutions predicted by optimists under the influence of innovative technologies of their time did not take place. Nevertheless, in the coming years, one can estimate the intensity with which radical digital transformations in technology influence the "digitalization" / digitization of education, as we see it today in culture, telecommunications, media, on TV. For example, we can note a significant increase in the volume of Russian-language educational digital resources, many of which are becoming available on the Internet.

Positive changes in education towards digitalization should probably be linked to the state ICT policy, which aims to provide universities with broadband Internet access and to form an IT-rich environment.

One of the important tasks of educational programs and projects is to achieve digital literacy, as new skills in evaluating and effective using programs and files in various digital formats (for example, the most common: text - MS Word, PDF, .txt, XML; graphic - BMP, GIF, JPEG, TIFF; sound - MP3, WAV; video - AVI, FLV, MPEG, etc.), which are supported by computers and Internet services. Thus, digital (electronic) books or ebooks are massively created and distributedwhich based on the availability of a printed source, can be divided into two types: electronic versions (copies) of a printed publication and books, originally produced in digital format, therefore they have different quality as well as educational value. Revolutionary transformations in publishing practice have been associated with the proliferation of online bookstores, such as Amazon.

Sociological studies show that in recent years the volume of digitized visual and audio information has been significantly highlighted in the increasing flow. The predominance of non-textual visual elements in the information received by users leads to an increase of the need to form visual literacy. Such training implies the development of visual perception of signs, symbols and their systems, the basic techniques of typography, text message design (cognitive-oriented, semantic, text and graphic accents), understanding of hidden meanings, codes and metaphors that are saturated with computer graphics or infographics, as well as photography, video, television image and advertising on the computer and Internet. According to some researchers, visual, multimedia components of the educational material or educational website allow to increase the rate of their developmentsignificantly.

Undoubtedly, these changes in technology, which began in the second half of the 20th century, entail the need for technological re-equipment of the education system, which can no longer be described as the only processes of computerization or informatization. Current trends of globalization, transformation and modernization affect all levels of the education system - from pre-school to additional. The digital revolution, understood in the narrow sense, as the transition from analog to digital devices and signal transmission technologies in the period of the middle of the last century, at the beginning of the XXI century, entered a new, higher level of implementation, encompassing more and more fields of activity, including education.

However, in this article we would like to consider one of the serious problems of digitalization of education, namely, the problem of multitasking. The keen interest of psychologists and teachers to this problem is inspired by the influence that digital technologies have on the achievements of students in the educational process. 
Nowadays, among the parents and some scientists, there is a widespread view that digital technologies are changing our lives and our brains. These conclusions followed the assumption of a fundamental change in the brain structure of children and adolescents under the influence of online interactions: "If the young brain is exposed to multitasking, triggered by the child's constant interaction with digital media, flickering images on the monitor or $\mathrm{TV}$, instant switching attention by pressing a button only then such a fast alternation of images can teach the brain to work in the mode of fast actions and superreactions "(Greenfield, P, 1984).

Some authors call the actions of students in multitasking mode a global condition for increasing productivity in the new millennium (Prensky, M. 2012, Gasser, U., Palfrey, J.). Others mark the generation iGeneration, for which digital technologies are not "tools", but part of the environment. For the generation of iGeneration WWW does not mean the World Wide Web, but Whatever, Whenever, Wherever, i.e. anything, anytime, anywhere. Many authors indicate that students of the iGenerationgeneration have a special need for multitasking, since their short-term memory has a large volume, speed, and efficiency (Rosen, L. 2007).

\section{Methodology}

Let us try to present an overview of some psychological and pedagogical research on multitasking in education, generated by the use of digital technologies. A review of research will help teachers make a well-considered decision about the possibilities and consequences of the use of digital technologies in the classroom, both directly by themselves and by students. Claiming that digital technologies are changing the traditional roles of a teacher and a student, we must clearly understand a kind of effects arised at the moment digital technologies are used in the classroom.

The problem of multitasking is one of the most discussed recently in management, ergonomics, psychology, neurophysiology and pedagogical communities abroad. At present, an idea about several meanings of the concept of "multitasking" has formed. First, multitasking in social psychology is understood as cognitive dissonance due to changing relationships in a social group (F. Hyder, L. Festinger). We are talking about the existence of a mismatch between the knowledge, representation, opinion of people within the social community (group). In the 70s. of XX -thcentury, "dissonance effects" were rethought in information terms and presented as a special case of the functioning of causal schemes (multitasking interface). Secondly, multitasking is interpreted as the result of a person being in an excess information environment. Such an environment arises from the simultaneous use of several channels for obtaining information. The spread and ease of access to information and communication technologies, social networks, and text messaging led users to understand the need to manage large amounts of streaming data in real time. Information and communication technologies freed students from the need to use class time to receive information. Information and communication technologies have created a space where teachers can teach students important skills in terms of modern economics. To some extent, these skills can be called engineering, the ability to detect, design and solve multitask problems, to collaborate in order to profit from constant interaction, establishing feedback and discussing common ideas. Multitasking challenges traditional thinking and teaching. Thirdly, multitasking can be understood as a consequence of understanding a problem that is fundamentally difficult or undecidable from the point of view of a person's technology. At present, it is generally accepted that multitasking involves the simultaneous execution of two or more functionally independent tasks, each of which has its own unique goals generated by various incentives, and its own special way of acting. Although multitasking is commonplace, little is known about when and why people perform more 
than one task at a time.Multitasking is a retronym that was introduced after it was realized what multitasking is. In ergonomic studies of multitasking, it was shown that people actually use multitasking, that is, they decompose a complex problem into components of the problem and successively solve them one after another. Multitasking allows people to achieve great results and participate in more activities. Participation in several tasks requiring simultaneous constant attention can be heuristically and practically significant. However, focusing on a variety of tasks can lead to errors and reduce overall performance. Losses of time and labor productivity in this case are up to $40 \%$. Group research projects in linguistics have great potential for multitasking. In the process of preparing the project, the student is in a state of multitasking simultaneously in several senses. First, the student himself feels cognitive dissonance, because it acts in a group. Students organize virtual educational communities in the group's social network. Secondly, multitasking arises due to the need to solve a complex problem that does not have analog solutions for the student and his immediate environment. Thirdly, the student, under the conditions set by the teacher, is obliged to act and look for a solution to the problem on the network using information and communication technologies. At the beginning of work, without pedagogical support, students are not able to realize the preparation of the project as a problem of multitasking and independently find strategies for managing the group, time and information. Students can be explained and shown how to act in multitasking mode. The pedagogical potential of the concept of multitasking can be seen in the fact that the teacher leads the student to understand the consequences of using certain technologies in multitasking mode, forms new technologies for working in a group or in an excess information environment. As soon as students realize that they can cope with multitasking by learning to distribute privileges, priorities and time, doing complex work brings them pleasure. This conclusion is supported by long-term observations. One of the important rewards that can motivate people to multitask is the stimulation provided by repeated participation in the multitasking mode. Students often choose the multitasking mode because it is more interesting, difficult and less boring than solving one traditional task. In some cases, they can take on several tasks for pure pleasure, even if their overall performance suffers.Decision-making research shows that multi-tasking preparedness should depend on expected results or consequences. Observations confirm the data of F. Davis, showing that there is a direct connection between the perceived ease and usefulness of using information and communication technologies and the motive for participating in multitasking. In psychology, the idea is that there are individual differences in multitasking ability. The ability to multitask manifests itself in impulsive people, focused on reward and maintaining authority. Such people react more sensitively to goals. In the process of preparing a project, a student is in a state of multitasking simultaneously in several senses. First, the student himself feels cognitive dissonance, because he acts in a group. Students organize virtual educational communities in the group's social network. Secondly, multitasking arises due to the need to solve a complex problem that does not have analog solutions for the student and his immediate environment. Thirdly, the student, under the conditions set by the teacher, is obliged to act and look for a solution of the problem in the network using information and communication technologies. At the beginning of work, without pedagogical support, students are not able to realize the preparation of the project as a problem of multitasking and independently find strategies for managing the group, time and information. Students can be explained and shown how to act in multitasking mode. The pedagogical potential of the concept of multitasking can be seen in the fact that the teacher leads the student to understand the consequences of using certain technologies in multitasking mode, forms new technologies for working in a group or in an excess information environment. As soon as students realize that they can cope with multitasking by learning to distribute privileges, priorities and time, doing complex work (creating a 
project on linguistics) brings them pleasure. This conclusion is supported by long-term observations. One of the most important benefits that can motivate students to multitask is the stimulation provided by multiple participation in the multitasking mode. Adults often choose a multitasking mode, because it is more interesting, difficult and less boring than solving one traditional problem. In some cases, they can take on several tasks for pure pleasure, even if their overall productivity suffers.

Smartphones and other mobile devices that students use during a class create a digital multitasking mode. The situation in Universities that has emerged after the widespread dissemination of digital technology is such that it is methodologically unproductive to place the observed effects of multitasking in the previous theoretical framework. New analytical models and new theories are needed. There is no doubt about the need for the emergence of new theoretical frameworks of interpretations when analyzing any phenomena that possess fundamental novelty. But in the case of digital multitasking it is not simple. On the one hand, multitasking itself is not a new phenomenon in the educational process. In the epistemological sense, the learning problem can be interpreted as multitasking planned by the teacher. Therefore, in its analysis and description, an ontologically unfamiliar field cannot arise (Bilyalova AA, Lyubova TV, Valeeva AR., 2017).

That is why the first pedagogical research of digital multitasking extrapolated the meanings and conclusions obtained in the decision making theory to the educational process. Most often, economists proceed from the following view: each person solves the problem of switching attention, i.e. determines the method and speed of information transfer at the moment when he is forced to make a decision or prioritize actions quickly (Speier, C., 2000). Simultaneously with the concept of "multitasking", such studies use the concepts of "information overload", "background multitasking", "switching attention" (McPeak, D. Rubinstein, J., Meyer, D., Evans, J., 2001), “attention interruption "(Speier, C., Valacich, J., Vessey, I., 2007)“ cognitive overload ”(Kirsch, D., 2000).

It is generally accepted in decision making theory that interruption of attention can increase productivity if interrupted tasks are simple and interruption forces a person to turn to a task that is substantially simpler than the primary one by the level of complexity. Setting and solving switching tasks (commutation) requires not only a large amount of time from a person for researching resources and planning resources, but also special skills, especially when the task has a critical moment of novelty.

Cognitive theory in the middle of the 20th century concluded that parallel processing of information can improve the efficiency of routine actions. Each shift of attention involves psychological costs. In most contexts, overall performance decreases in proportion to the number of switches. Conversely, a quick switch from one mental task to another can reduce productivity, especially if both tasks are complex.

Psychologists Meyer, D., G. Small, Jones, Q. and others reduce research to the search for a multitasking substrate in the human brain. It is argued that each shift of attention from one task to another requires the activation of various neural circuits and is probably coordinated by the frontal lobes of the brain. The prefrontal cortex of the brain regulates a person's cognitive abilities, problem solving, state of attention, and suppression of emotional impulses. For those students who are not able to learn from past mistakes, the function of the prefrontal cortex is usually impaired. Their actions are not based on experience, but on what they want at the moment. We conclude that a student with a good work of the prefrontal cortex is able to learn the following - starting to work in a complex project as soon as possible, he will provide himself more time and he will have less reason to worry that he will not have time to pass it on time. A student with a reduced function of the prefrontal cortex does not take into account past troubles and failures and will constantly postpone everything to the last moment. Within the framework of such a theoretical approach, the possibility of a teacher's other actions is denied, besides his 
influence on the students' abilities or innate qualities (Sanbonmatsu, D., Strayer, D., Medeiros-Ward, N., Watson, J.). Here one can identify the range of judgments from the complete negation of the very possibility of multitasking (Medina, J., 2008) to the statement of the inevitability of a change in the brain - the "digital psychomorphosis" under the influence of human interaction with digital technologies (Prensky, M. 2012, M. Sandomirsky).

Some researchers (Medina, J., 2008,Strayer, D., 2012) insistthat evolutionary brain is not adapted to multitasking. Man is arranged in such a way that in conditions of a constantly unstable external environment, the problem of survival always comes to the fore. The flexibility of the brain, its ability to solve arising problemsinstantly can be considered an evolutionary effect. At the same time, the ability of the brain to unstable and changing in its main parameterswork evolved evolutionarily the loss of those qualities that would allow it to process incoming information in parallel. Solving one problem is possible by minimizing the value of another problem. Every time the brain switches to solve a new problem, a large amount of energy and time is consumed. Conclusion of Medina, J. is ambiguous: training in a peer group is one of the types of multitasking and entails a nervous strain generated by cognitive dissonance. Multitasking in the educational process is therefore harmful. Since educational institutions actually encourage multitasking, students must be transferred to home schooling.

Nervous overstrain is exacerbated if the student uses different digital technologies and mobile devices in the classroom. Jones, Q., Chang, S., Viadero, D., Ophir, E. indicate that digital multitasking is potentially disruptive to students. Students become lethargic and boring people. They do not enjoy reading, they have problems using words, and social networks use to certify their own identity. Jones Q. and others believe that the multitasking mode also affects the attitude of students towards themselves. Programming the brain on the background of multitasking, video and audio stimulation upsets the balance of operational and long-term memory, the syndrome of the limbic system develops (Small G., 2011).

Constant immersion in the redundant information environment leads to the fact that the student uses an individual tactic of avoiding information ("the phenomenon of information output"), the essence of which is that a person ignores relevant and useful information, because there is too much of it to understand it and adopt it (Savolainen, P., Mannering, F., 2008). Sometimes, there is a rejection of the comprehension of information and fixation on a quick decision, the so-called "paradox of choice".

Student experiences paralysis of the will facing to grandeur and the volume of the tasks assigned to him, therefore, is fixed on the first solution that came to mind. There is a well-known fact from teaching practice: despite information literacy, a student cannot select the necessary and sufficient number of information sources. This often leads to a random selection of sources and materials.

The aggravation of the information overload problem occurred after the advent of $\mathrm{Web}$ 2.0 tools. There was a situation in which a large amount of the most significant information comes in simultaneously with insignificant information, both of which are available in digital rather than printed form. The nature of the tools Web 2.0 contributes to the expansion of the information aspect of the educational process. We are talking about the perceived impermanence and variability of educational content, redundant information environment with information resources of various formats and types available to users (blogs, wikis, RSS feeds, podcasts, social bookmarks). Due to the fact that Web 2.0 tools provide and encourage rapid updating of the material, the student has an expectation of constant novelty, which can be satisfied by the generation of surface and ephemeral changes, recomposing the existing material when it is reused. There are questions: if an encyclopedia or textbook is presented in a wiki format, can we talk about a "classical 
textbook", "educational standard", and "final" form of a document? The problem of novelty of knowledge and information loses its former meaning (Keen A.).

In contrast tooverload and switching attention information, the concept of "digital multitasking" has a fundamental novelty and therefore must be analyzed in another conceptual field. Since the beginning of the XXI century under the influence of the philosophy of consciousness D. Chalmers, some attempts are being made to form a new theoretical base for the research of digital multitasking. The new research approach proceeds from the position that consciousness originates in any information system; therefore, a person is a system for processing information. An additional statement of the principles of coherence, the correlation of consciousness with a certain type of information system, makes it possible to imagine a student acting in digital multitasking mode as an organization having common and structural coherence. It is not the mental qualities of a person that are investigated, but his conscious (phenomenal) experience on indirect signs behavior change (Hembrooke H., \& Gay, G., 2003). There are many opportunities for pedagogical activities. However, several articles state that the ability of the generation iGeneration, born in the mid-1990s, to integrate information in a special way is nothing more than a delusion (Willingham, D., 2009). The experience of multitasking does not give young people advantages and does not bring benefits in comparison with adults, considerVerhaeghen, P., Salthouse.

\section{Results}

Digital multitasking in the educational process occurs when digital technologies are used in the classroom. So, let's take a closer look at the data that was obtained by researchers in various circumstances:

1. Digital technologies are used by teachers. Specialists in the cognitive sphere pay a lot of attention to analyzing the consequences of the use of digital technologies by the teacher, for example, they learn the ways of interpreting and the effectiveness of memorizing training text by the students in multimedia classes. They point out that sometimes a multimedia lesson consists of two sequences of unrelated messages - a verbal and a video ones. Teachers, due to inexperience or lack of understanding of the consequences of their actions, can separate the studied text and the accompanying it graphics in time and / or space. It is assumed that the student should simultaneously understand both the text and the video sequence and coordinate the process of understanding both. The student is experiencing a heavy load, he must keep both messages in his memory at the same time. There is a possibility that he will not be able to do it successfully. Analysis of posts in social networks shows that users open and read short and simple messages, preferring not to open long and overloaded ones.This implies, as Rubinstein and J., Meyer, D. (2001) show that in a case of a conflict of text and graphics, multimedia technologies are ineffective.Willingham, D. (2009) states that the teacher's use of digital technology does not mean that students will learn better. Moreover, the methods of applying digital technologies for the benefit of students' academic performance to the teacher himself are not always obvious. Sometimes different learning outcomes are rooted not in the strengths or weaknesses of multimedia, but in differences between students. The amount of RAM varies from person to person. So a multimedia lesson that will benefit a student with a large amount of RAM can be detrimental to a student with a smaller volume. In a multimedia environment, the understanding and interpretation of content occurs differently than in traditional conditions. The transition from a two-dimensional picture to a three-dimensional moving video sequences can also create problems for the perception of content in some students. 
2. Digital technologies are used by students as directed by the teacher, which implies a local network and / or free Internet access (.Jungo, R. 2013, Ophir E., 2009). Under hypertext conditions, if a student uses related links to see the definition of a word, the reading comprehension is violated. The decision to follow the link, and then returning to the main text destroys the continuity of reading and endangers the possibility of building logic. The degree of influence of hyperlinks on reading comprehension depends on the volume of the student's memory and on the availability of prior knowledge. At the same time, students who have a greater amount of RAM or prior knowledge about the subject of the text, better assimilate the material, despite the hyperlinks. Studies of online learning mode have shown that students finally print online materials to avoid overloading (Ophir, E., 2006) or limit the number of websites they visit (Hartmann, M. 2003).

3. Digital technologies are used by students furtively on the contrary to the teacher's instructions along with the performance of classroom work. Researchers have repeatedly analyzed the functions of attention and memory of students at the moment when students read SMS messages or make entries in social networks (Gantz, JF, 20010, Jones, C. \& Shao, B., 2011, Foehr, U., 2006). Students were asked about the mode (frequency and duration) of using smartphones, instant messaging services in the classroom, volume and number of messages sent to each other.

\section{Discussion}

Most pedagogical studies are conducted from the standpoint of the methodological dogma of operationalism: researchers observe the actions of students, sometimes they transcribe their written texts, and keep diary. Operationalism is a common methodological setting in anthropology, psychology, and pedagogy, widespread in the 20th centuryand it consists in the fact that the researcher captures the actions of people in different ways (photo, audio, video), and then analyzes them, using certain approaches. Operationalism had its own strong point, and it is still relevant: it will be impossible to imagine the consequences of the use of digital technologies in the audience, if not to analyze the actions of students. In early pedagogical studies, the automatic use of a certain set of old and rather annoying concepts, sounding banal thoughts, which were formed almost a century ago, should be noted. The real picture of digital multitasking is simplified or distorted. There is a feeling of pettiness or unimportance of observations and conclusions. It is not by chance that digital multitasking appears in articles in the paradigm of collecting exotic technologies and devices:

In recent articles, there is a concern about the idea of representativeness of a study to legitimize a chosen research approach. This is manifested in an increase in a sample size. Researches in the 90-th were conducted with 7-9 students butin $2014-1,479$ people took part in the studies (Ravizza, S., Hambrick, D., Fenn, K., 2014). The object of research is changing: instead of objective indicators - speeds of cognitive processes, for example, it describes how multitasking is experienced by a student (Lavie, N., 2005). In general, attempts to develop new theoretical boundaries of digital multitasking analysis can hardly be considered as successful so far.

Currently, among teachers and parents of different countries there is a widespread desire to save schoolchildren and students from multitasking. In the opinion of the author, this position is naive. It seems that the key solution may consist of a statement of facts and a discussion of strategies. In our opinion, training can include a structured conversation with students about the possibilities and consequences of multitasking (Crenshow D., 20010). Students can share alternative coping strategies that they use to cope with information overload.

The teacher can help students cope with the effects of multitasking, namely: 
1) teach to focus on only one type of activity; from time to time to offer students to close laptops, smartphones and participate in classroom discussions. Some teachers go further: close an access to $\mathrm{Wi}-\mathrm{Fi}$ in classrooms, at least during the control and verification work;

2) limit the amount of information. This means the advisory nature of the choice of sources of information;

3) adopt and master digital technologies, while at the same time ensuring the limits of their use from time to time to teach students to reflect, plan and organize. It is important to find the direction in which invisible shifts and changes take place in students.

Thus, in the analyzed monographs and articles it is stated:

- digital multitasking in the educational process occursat the time of use of digital technology in the audience;

- Digital multitasking does not create major obstacles to learning. Despite this, researchers confidently conclude that switching attention when using digital technology significantly increases the amount of time needed to complete a learning task. Distraction of attention and time spent on switching from task to task will have a negative impact on the academic performance of students;

- The use of digital technology by the teacher creates a multitasking mode for the student. The specific use of digital technology at one time or another class is determined by the goals that the teacher sets;

- student use of mobile devices (devices) in the classroom may entail a negative effect on academic performance;

- Digital multitasking can qualitatively change learning, because the student relies on different information processing systems that differ in their degree of flexibility, that is, he chooses what information structure to use in a particular case.

\section{Conclusions}

1. In the analyzed studies of digital multitasking in education, there is a shift in attitudes and emphasis from the methodology of operationalism to attempts to apply the methodology of an analytical philosophy of consciousness and / or postmodern philosophy. This allows you to analyze the intentions, motives of the participants in the educational process and thereby define new conceptual boundaries of digital multitasking.

2. The object of research is changing: instead of the speed of various cognitive processes, the author explores the motives for using digital technologies or experiencing (qualia) participants in the educational process.

3. Preoccupation with the representativeness of the study forces the author to expand the sample size.

4. Ingeneral, students focus on the perceived usefulness of technology and the perceived ease of use of technology. The usefulness and simplicity of technology determines the intention to use it and affects the motivation of the individual.

\section{References}

1. Allen, D., Shoard, M. Spreading the Load: Mobile Information and Communications Technologies and their Effect on Information Overload. Information Research, 2005, 10 (2), p. 227.

2. Bawden, D., Robinson, L. The Dark Side of Information: Overload, Anxiety and other Paradoxes and Pathologies // Journal of Information Science, XX (X) 2008, 1-12. 
3. Bilyalova AA, Lyubova TV, Valeeva AR. Multicultural Education and Its Targets in The Process Of Intercultural Competence Formation: (Based On Foreign Languages Teaching Experience) / International Journal of Scientific Study September 2017. Vol 5. Issue 6 5(6):93-96.

4. Chang, S., Ley, K. A Learning Strategy to compensate for Cognitive Overload in Online Learning. Journal of Interactive Online Learning, 2006, 5(1), 104-117.

[Electronic resource]. Access mode: http: // www.ncolr.org/jiol /issues/PDF/5.1.8.pdf.

5. Castaño-Muñoz, J., Duart, J. M., \& Sancho-Vinuesa, T. 2014. The Internet in face-toface higher education: Can interactive learning improve academic achievement?. British Journal of Educational Technology, 45(1), 149-159

6. Davis F.D., 1989. Perceived usefulness, perceived ease of use and user acceptance of information technology. MIS Quarterly 13(3), 319-340.

7. Foehr, U. Media Multitasking among American Youth: Prevalence, Predictors and Pairings. Menlo Park, CA: Henry J. Kaiser Family Foundation. 2006 [Electronic resource]. Access mode : http: // www.kff.org/entmedia/upload/7592.pdf,

8. Gasser, U., Palfrey, J. Mastering Multitasking// Educational leadership, 66 (6), 14-19. [Electronic resource]. Access mode : http: //

cf.linnbenton.edu/wed/dev/hakek/upload/mutli1.pdf.

9. Gantz, J. F. The Expanding Digital Universe: A Forecast of Worldwide Information Growth through 2010. Framingham, MA: IDC [Electronic resource]. Access mode : http: // www.emc.com/collateral /analyst-reports /expanding-digital-idc-whitepaper.pdf.

10. Greenfield, P. Mind and Media: the Effects of Television, Video Games and Computers. Harvard University Press, 1984. [Electronic resource]. Access mode : http: //www.cdmc.ucla.edu/Mind_and_Media_files /MMCHP1.pdf.

11. Ignatov $\mathrm{N}$. Yu. Multitasking and student performance // Open and distance education. 2014. 3 (55). Pp. 5-11.

12. Hembrooke H., \& Gay, G. The Laptop and the Lecture: The Effects of Multitasking in Learning Environments. Journal of Computing in Higher Education, 2003, 15(1), 4664. [Electronic resource]. Access mode: http: // www.ugr.es/ victorhs/gbd/docs/10.1.1.9.9018.pdf.

13. S. T., Horvitz, E. Disruption and Recovery of Computing Tasks [Electronic resource]. Access mode : http: // research.microsoft.com/enus/um/people/horvitz/chi_2007_iqbal_horvitz.pdf

14. Jones, Q., Ravid, G., Rafaeli, S. Information Overload and The Message Dynamics of Online Inte-raction Spaces: A Theoretical Model and Empirical Exploration. InformationSystemResearch, 2004, 15(2), 194-210.

15. Jones, Q., Ravid, G., Rafaeli, S. Information Overload and The Message Dynamics of Online Inte- raction Spaces: A Theoretical Model and Empirical Exploration.

Information System Research, 2004, (2), 194-210. [Electronic resource]. Access mode : http: // www.ravid.org/gilad/isr.pdf,.

16. Jones, C. \& Shao, B. The NET Generation and Digital Natives: Implications for Higher Education. York: Higher Education Academy, 2011 [Electronic resource]. Access mode : http: // oro.open.ac.uk/30014 /

17. Jungo, R. In-class Multitasking and Academic Performance. Computers in Human Behavior, 2012, Vol. 28, Issue 6, 2236-2243. 
18. Keen A. The Cult of the Amateur: How Today's Internet is Killing our Culture.

Nicholas Bradley Publishing, London, 2007. [Electronic resource]. Access mode : http:

// www.tc.umn.edu/ mill3239/home/presentations/panel3-1.pdf.

19. Kirsch, D. Few Thoughts on Cognitive Overload. Intellectica, 2000, 1(30), 19-51

[Electronic resource]. Access mode : http:

//adrenaline.ucsd.edu/kirsh/Articles/Overload/Cognitive_Overload.pdf.

20. Levine, L. E., Waite, B. M., Bowman, L. L. Can Students really Multitask? Computers \& Education, Vol. 54, Iss. 4, May 2010, 927-931.

21. Lavie, N. Distracted and confused? Selective Attention under Load. TRENDS in Cognitive Sciences, 2005, 9(2), 75-82.

22. Lyubova T.V., Gilfanova G.T. Scientific researches analysis in digital multitasking field of educational process in modern universities and determination of new conceptual boundaries of it. Integrated Science in Digital Age , - ICIS 2019. -- №78. pp. 277-288

23. McPeak, D. Multitasking vs Switch-tasking [Electronic resource]. Access mode : http: // inci- dent-prevention.com/ip-articles /multitasking-vs-switch-tasking-what-s-thedifference

24. Medina, J. Brain Rules: 12 Principles for Surviving and Thriving at Work, Home, and School. Seatle, Pear Press, 2008. [Electronic resource]. Access mode : http: // ext100.wsu.edu/pierce/wp- content/uploads/sites/9/2014/01/BrainRules-JohnMedinaMediaKit.pdf.

25. Ophir, E., Nass, C., Wagner, A. D. Cognitive Control in Media Multitaskers. Proceedings of the National Academy of Sciences of the United States of America, 2009, 106 (37), 15583-15587 [Electronic resource]. Access mode : doi:10.1073/pnas.0903620106.

26. Prensky, M. From Digital Natives to Digital Wisdom: Hopeful Essays to 21 st Century Learning. Corwin Press, 2012. [Electronic resource]. Access mode : http: // marcprensky.com/from-digital- natives-to-digital-wisdom.

27. Ravizza, S., Hambrick, D., Fenn, K. Non-academic Internet use in the Classroom is negatively related to Classroom Learning Regardless of Intellectual Ability: Computers \& Education, 2014, 10(4),109-114.

28. Rosen, L. Teaching the iGeneration. Educational Leadership, 2007, 68(5), 10-15 [Electronic resource]. Access mode: http:

//www.ascd.org/publications/educational-leadership/feb11/vol68/num05/Teachingthe-iGeneration.aspx.

29. Rosen, L. D., Carrier, L. M., Cheever, N. A. Facebook And Texting Made Me Do It: Media- Induced Task-Switching While Studying. Computers in Human Behavior, Volume 29, Issue 3, May 2013, 948-958.

30. Rubinstein, J., Meyer, D., Evans, J. Executive Control of Cognitive Processes in Task switching. Journal of Experimental Psychology: Human Perception and Performance, 2001, 27(4), p. 763-797.

31. Sanbonmatsu, D., Strayer, D., Medeiros-Ward, N., Watson, J. Who Multi-Tasks and Why? Multi- Tasking Ability, Perceived Multi-Tasking Ability, Impulsivity, and Sensation Seeking//PLoS ONE, 2013, 8(1) [Electronic resource]. Access mode : http: // www.plosone.org/article/info:doi/10.1371/journal.pone.0054 402.

32. Savolainen, P., Mannering, F. Effectiveness of Motorcycle Training and Motorcyclists' Risk- Taking Behavior. Transportation Research Record: Journal of the Transportation 
Research Board, 2008, vol. 2031/2007, 52-58 [Electronic resource]. Access mode : http: // trb.metapress.com/content/3332n8q718k25830.

33. Small, G., Vorgan, G. Ibrain: Surviving the technological alteration of the modern mind. NewYork: Collins Living, 2008 [Electronic resource]. Access mode : http:// www.barnesandnoble.com/sample/read /9780061340345.

34. Study: Multitasking hinders learning. eSchool News. 2006, July 26. [Electronic resource]. Access mode: http: // www.eschoolnews.com/2006/07/26/studymultitasking-hinders-learning.

35. Verhaeghen, P., Salthouse, T. Meta-Analyses of Age-Cognition Relations in Adulthood: Estimates of Linear and Nonlinear Age Effects and Structural Models // Psychological Bulletin 1997, Vol. 122, No. 3, 231-249.No. 3, 231-249. [Electronic resource]. Access mode : http: // www.ncbi.nlm.nih.gov/pubmed/9354147.

36. Viadero, D. Instant Messaging found to slow Students' Reading. Education Week, 2008, August15. [Electronic resource]. Access mode :www.edweek.org/ew/articles/2008/08/27/01 im.h28.html.

37. Willingham, D. Have Technology and Multitasking Rewired How Students Learn? American Educator, 2009, 34 (2), 23-28. [Electronic resource]. Access mode : http: // er- ic.ed.gov/?id=EJ88. 